\title{
BMJ Open Cohort profile: the LHIV-Manitoba clinical cohort of people living with HIV in Manitoba, Canada
}

\author{
Leigh M McClarty (i) , ${ }^{1}$ Eve Cheuk, ${ }^{1}$ Laurie Ireland, ${ }^{2}$ Claire Kendall, ${ }^{3}$ \\ Christine Bibeau, ${ }^{4}$ Carla Loeppky, ${ }^{5}$ Ken Kasper, ${ }^{6}$ Yoav Keynan, ${ }^{7}$ James Blanchard, ${ }^{1}$ \\ Marissa Becker ${ }^{1}$
}

To cite: McClarty LM, Cheuk E, Ireland L, et al. Cohort profile: the LHIV-Manitoba clinical cohort of people living with HIV in Manitoba, Canada. BMJ Open 2020;10:e034259. doi:10.1136/ bmjopen-2019-034259

- Prepublication history for this paper is available online. To view these files, please visit the journal online (http://dx.doi org/10.1136/bmjopen-2019034259).

Received 12 September 2019 Revised 06 February 2020 Accepted 06 May 2020
Check for updates

(c) Author(s) (or their employer(s)) 2020. Re-use permitted under CC BY-NC. No commercial re-use. See rights and permissions. Published by BMJ.

For numbered affiliations see end of article.

Correspondence to Leigh M McClarty; ummcclar@myumanitoba.ca

\section{ABSTRACT}

Purpose The LHIV-Manitoba cohort was developed as a way to provide a comprehensive source of HIV-related health information in the central Canadian Prairie province of Manitoba. The cohort will provide important information as we aim to better understand local HIV epidemiology and address key knowledge and practice gaps in HIV prevention, treatment and care programming in the province.

Participants In total, 890 individuals, aged 18 or older and living or receiving HIV care in Manitoba are enrolled in the cohort. A complete clinical dataset exists for 725 participants, which includes variables on sociodemographic characteristics, comorbidities and co-infections, self-reported HIV exposure categories and HIV clinical indicators. A limited clinical dataset exists for an additional 165 individuals who were enrolled posthumously. $97.5 \%$ of cohort participants' clinical records are linked to provincial administrative health datasets.

Findings to date The average age of cohort participants is 49.7 years. Approximately three-quarters of participants are male, $42 \%$ self-identified as white and $42 \%$ as Indigenous. The majority of participants (64\%) reported condomless vaginal sex as a risk exposure for HIV. Nearly one-fifth (18\%) of participants have an active hepatitis $C$ virus infection and the cohort's median CD4 count increased from 316 cells $/ \mathrm{mm}^{3}$ to 518 cells $/ \mathrm{mm}^{3}$ between time of entry into care and end of the first quarter in 2019. Future plans The LHIV-Manitoba cohort is an open cohort, and as such, participant enrolment, data collection and analyses will be continually ongoing. Future analyses will focus on the impact of provincial drug plans on clinical outcomes, determinants of mortality among cohort participants and deriving estimates for a local HIV care cascade.

\section{INTRODUCTION}

Annual reports on HIV in Canada consistently highlight heterogeneous, although relatively stable, epidemiological trends across the country. ${ }^{1}$ At the end of 2016, the Public Health Agency of Canada (PHAC) estimated that 63110 people were living with HIV in the country and 2402 people were newly diagnosed in 2017. ${ }^{1}$ Nationally, new HIV diagnoses

\section{Strengths and limitations of this study}

- This cohort is the first comprehensive source of health data compiled from people living with HIV in Manitoba and will provide important opportunities for understanding clinical care needs, gaps and outcomes of people living with HIV in the province.

- Cohort enrolment protocols are clinic based, and as such, this cohort may not be representative of people living with HIV who are suboptimally engaged in care. One key strategy to circumvent the misinterpretation of analyses derived from cohort data will be to involve Manitoba HIV Program's clients and their providers in the analysis, interpretation and knowledge translation processes.

- Because this cohort is embedded within the Manitoba HIV Program, and stakeholders within government and the community of people with lived experience are actively involved in its development, the data from the cohort will be able to facilitate analyses that can inform programming and provincial policy on adequately resourcing HIV-related health services.

disproportionately occur among Indigenous (First Nations, Inuit and Métis) populations and people who have immigrated from countries where HIV is endemic. ${ }^{1}$ The greatest proportion of prevalent HIV infections in nearly all Canadian provinces is attributed to condomless sex between men; however, notable exceptions include the central Prairie provinces of Saskatchewan and Manitoba, where most incident and prevalent cases are attributable to injection drug use and heterosexual transmission, respectively. ${ }^{2-4}$ The rates of new HIV diagnoses per 100000 population in Manitoba have been consistently higher than the national average, ranging from 9.5 new diagnoses in 2014 to 6.6 in 2016 and 2017. ${ }^{145}$ Despite evidence of unique epidemiology and disproportionately high rates of infection, relatively little research addresses HIV epidemiology in the Canadian Prairies, ${ }^{6}$ 
and there is a specific lack of published research focusing on Manitoba.

Current HIV epidemiological data for Manitoba are primarily derived from surveillance reports produced by PHAC and the provincial health department, Manitoba Health, Seniors and Active Living (MHSAL).${ }^{12}$ In 2017, MHSAL reported 89 new cases of HIV in the province with the majority of cases occurring in Winnipeg $(81 \%)$ and a disproportionately high incidence among women when compared with national rates. ${ }^{2}$ While useful for providing basic information about patterns and trends in HIV infection in Manitoba, these reports only provide aggregate-level demographic and geographic analyses of the previous year's incident infections (new diagnoses and/or cases introduced to, but not acquired in, the province). Without the clinical data, these reports are limited in their ability to inform specific research questions or programmatic decisions for HIV care and service delivery in the province.

In 2013, as part of a Canadian Institutes of Health Research-funded programme of research, the 'Advancing Primary Healthcare for Persons Living with HIV in Canada' (LHIV) study provided support for the establishment of a prospective clinical cohort of people living with HIV in Manitoba. This clinical cohort is the first comprehensive source of HIV-specific health data in Manitoba and provides important opportunities to address key knowledge gaps in local HIV epidemiology-including patterns of healthcare utilisation and relevant clinical outcomesand to understand healthcare needs of people living with HIV in the province. Similar cohorts have been developed and are now are well-established in other Canadian provinces, including British Columbia ${ }^{7}$ and Ontario. ${ }^{8}$ This article provides an overview of processes and procedures involved in cohort development and maintenance, and describes demographic-related and HIV-related characteristics of LHIV-Manitoba cohort participants.

\section{COHORT DESCRIPTION}

\section{Study setting}

Established in 2007, the Manitoba HIV Program is the primary provider of treatment, care and support for people living with HIV in the province. The Manitoba HIV Program employs a multidisciplinary care model in which HIV specialist physicians, family physicians, nurses (including nurse practitioners), pharmacists, dietitians, social workers and other allied service providers provide comprehensive HIV care out of three clinic sites-a hospital-based outpatient clinic and a community health centre in Manitoba's capital city, Winnipeg, and a nurse-run health access centre in Brandon, a semi-urban city approximately $200 \mathrm{~km}$ west of Winnipeg. While all three clinic sites follow a multidisciplinary care model and each have links to health promotion programmes and resources, some differences in organisation exist. For example, the clinic at the community health centre is run by family doctors and each client at that site is assigned to a specific physician and nurse couple. Meanwhile, physicians at the hospital-based clinic are infectious disease specialists and all clients of the hospital clinic in Winnipeg and the nurse-run clinic in Brandon are seen by a rotating roster of providers.

\section{Patient and public involvement}

Although arising from a research project, the LHIVManitoba cohort is strategically embedded within the Manitoba HIV Program and the local study team partners with stakeholders within the Manitoba HIV Program and other community clinics, MHSAL, the Manitoba First Nations AIDS Working Group and the LHIV study's Community Scholar Program, ${ }^{9}$ all of whom have been actively involved in the development of the cohort. Study design and enrolment procedures were conducted by researchers and trainees within the LHIV study team. Throughout the development of the cohort, engagement through community forums and meetings with key stakeholders provided information about the objectives of the LHIV-Manitoba cohort and what it meant to be a participant, while actively seeking input about research questions that could be addressed using cohort data. As such, findings from cohort data are expected to have direct relevance and applicability for both HIV care programming and provincial health policy. Dissemination and knowledge translation activities with all key stakeholders, including community members, community-based organisations and key policy-makers and decision-makers, will be facilitated by study team members and Manitoba HIV Program staff.

\section{Enrolment procedures}

Recruitment began at one clinic site in October 2013 and was fully implemented across all Manitoba HIV Program sites by January 2014. Data collection, linkage to administrative health databases and data cleaning and analyses began in early 2017. Both enrolment and linkage are ongoing.

The enrolment process is illustrated in figure 1. Inclusion criteria for the cohort are broad: participants must be at least 18 years of age and either living with HIV in Manitoba or receiving HIV care in Manitoba. Individuals who met these criteria but are under the jurisdiction of the Public Guardian and Trustee of Manitoba, or were otherwise unable to make decisions pertaining to their own healthcare, are deemed ineligible for participation in the cohort.

Recruitment and informed consent procedures take place within the Manitoba HIV Program clinics; clients who present to clinic are approached by a nurse or another allied healthcare provider and asked whether they are willing to speak to a research assistant about participating in a research project. If a client is agreeable, a research assistant meets with them to explain the purpose, context and methods for the LHIV-Manitoba cohort study, and reviews the informed consent form to determine whether the person is interested, willing and able to participate. 


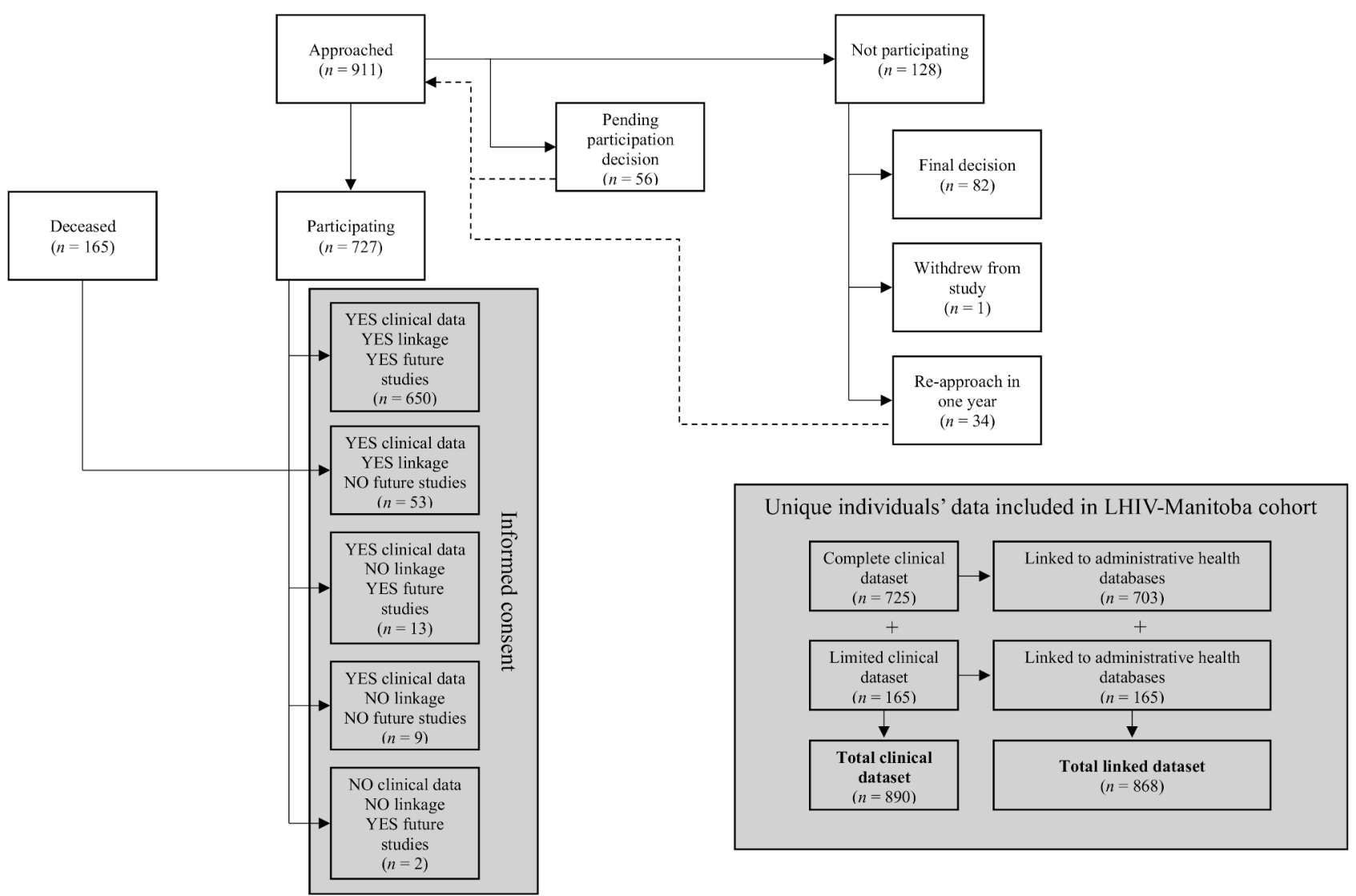

Figure 1 Recruitment, informed consent and data collection processes for the LHIV-Manitoba cohort.

Participants have the opportunity to take part in any combination of three separate components of the LHIVManitoba cohort: (1) have their clinical data collected; and/or (2) have their clinical data linked to administrative health data that is routinely collected by the province; and/or (3) indicate interest in being approached about future HIV research studies. Clients who are not ready to decide immediately can defer their decision to participate in the cohort and request to meet with the research assistant at a later date to reconsider their participation. Study staff keeps track of individuals who asked to defer their decision to participant and actively follow-up with them at their next clinic appointment in a year's time, depending on the stated preference.

\section{Study measures, data sources and data collection}

Clinical data are manually extracted from electronic medical records (EMR) - or from paper charts for clinical information recorded prior to the introduction of EMR to clinic sites-within the Manitoba HIV Program's clinic sites by the first author and two trained extractors, and then entered into an encrypted, password protected Excel spreadsheet for consenting participants. Standardised definitions were developed for each variable to ensure quality and consistency of data abstracted from clinical records. Manitoba HIV Program's clinicians who had entered data into clinical records were consulted for instances in which information to be collected was unclear or ambiguous. A complete clinical dataset for the
LHIV-Manitoba cohort includes variables on participants' sociodemographic characteristics (age, sex, geographic location of residence and self-identified ethnicity), comorbid chronic and mental health diagnoses, opportunistic infections, and other co-infections (occurring within 6 months of presentation to HIV care), including Hepatitis C virus (HCV); recorded HIV exposure categories; date and geographic location of first positive HIV test; CD4 count at time of diagnosis, at time of antiretroviral therapy (ART) initiation, and at the end of the second and fourth quarters of each year, beginning in 2017; date of first ART initiation; current ART regimen (collected biannually, beginning in 2017); alcohol and drug use, including injection drug use; and type of prescription pharmaceutical insurance coverage (collected biannually, beginning in 2017).

The study's institutional ethics approvals also allow data from deceased clients of the Manitoba HIV Program to be collected via retrospective chart reviews. A limited dataset is extracted from clinical records of deceased individuals, which comprises a subset of the aforementioned clinical datasets, excluding all comorbidity and co-infection data from clinical records, except for HCV, treatment regimen data and prescription pharmaceutical insurance data. Including data from deceased clients provides an important opportunity to explore and better understand determinants of mortality among people living with HIV in Manitoba. This has been identified as an area of 
particular interest to the Manitoba HIV Program, which, up to now, has not been adequately explored. Furthermore, the inclusion of these data helps to ensure broader generalisability of our findings from the cohort.

For individuals who were enrolled posthumously, and for participants who provide consent to data linkage, anonymised, de-identified clinical data are linked to provincial administrative health databases housed at MHSAL. Manitoba's administrative health datasets include individual-level records for nearly all contacts with the provincial healthcare system, including physician visits, hospital admissions, pharmaceutical prescription dispensations and laboratory testing. ${ }^{10}$ Linkage between clinical and administrative datasets is done through matching an individual's unique Personal Health Identification Number (PHIN) within both datasets. Before linked datasets are returned to the study team, MHSAL scrambles PHINs to de-identify the datasets and maintain participant anonymity. ${ }^{11}$

\section{Characteristics of study participants}

As of 31 March 2019, 890 unique individuals are included in the cohort (figure 1). A complete clinical dataset exists for $725(81.5 \%)$ cohort participants who agreed to have their data reviewed and extracted from clinical records within the Manitoba HIV Program. A limited clinical dataset exists for an additional 165 individuals whose clinical records were reviewed posthumously. Nearly, all individual-level clinical data are also linked to provincial administrative health datasets $(n=868,97.5 \%)$. At the end of the first quarter of 2019, 676 cohort participants $(76.0 \%)$ were alive and $214(24.0 \%)$ were deceased.

Select sociodemographic characteristics and outcomes of cohort participants are presented in table 1 and compared with the larger Manitoba HIV Program's client population. The average age of cohort participants at the end of the first quarter of 2019 (or at time of death, for participants who were deceased by 31 March 2019) was $49.7 \pm 11.9$ years. The majority of cohort participants are male $(71.2 \%)$, over $80 \%$ reported being either white $(42.4 \%)$ or Indigenous $(41.6 \%)$, while an additional $10.9 \%$ self-identified as an ethnicity categorised as African/Caribbean/black. The geographic distribution of cohort participants is primarily concentrated in Winnipeg $(80.8 \%$ ), while $1.4 \%$ of cohort participants live outside of Manitoba.

\section{FINDINGS TO DATE}

Analyses from the LHIV-Manitoba cohort are ongoing; a summary of preliminary findings is provided below.

\section{Representativeness and distribution of key outcomes within the LHIV-Manitoba cohort}

Given the research and programmatic potential of this cohort, it is of particular interest to understand whether, and to what extent, the demographic profile of cohort participants is representative of the larger Manitoba
HIV Program client population (table 1). Although similar in age structure, compared with the Manitoba HIV Program's client population, cohort participants are significantly more likely to be $\geq 40$ years $(78.9 \%$ vs $70.0 \%$, $\mathrm{p}<0.05)$. Compared with the Manitoba HIV Program, the cohort includes significantly more men $(71.2 \%$ vs $64.7 \% ; \mathrm{p}=0.001)$ and individuals who self-identify as white $(42.3 \%$ vs $30.0 \%, \mathrm{p}<0.001)$ or Indigenous $(41.5 \%$ vs $33.0 \%, \mathrm{p}<0.001)$ are greater in the LHIV-Manitoba cohort, while African/Caribbean/black clients are underrepresented ( $10.9 \%$ vs $15.8 \%, \mathrm{p}<0.001)$. The geographic distribution of cohort participants is similar to that of the larger client population, with the large majority of participants residing in Winnipeg ( $80.8 \%$ vs $79.6 \%$, $\mathrm{p}=0.486$ ).

\section{HIV-specific clinical indicators, co-infections and comorbidities}

Selected clinical indicators, analysed by sex, are presented in table 2. Preliminary findings from cohort participants' clinical data highlight similar trends to those seen in the most recent Manitoba HIV Program's annual reports. ${ }^{12}{ }^{13}$ While a substantial proportion of cohort participants presented late to HIV care, with $57.0 \%$ having initial $\mathrm{CD} 4$ counts $\leq 350$ cells $/ \mathrm{mm}^{3}, 52.3 \%$ of most recent CD4 counts are $>500$ cells $/ \mathrm{mm}^{3}$. In general, the proportion of participants with suppressed viral loads ( $<200 \mathrm{HIV}$ RNA copies $/ \mathrm{mL}$ ) increased from their initial to most recent clinic visit ( $50.5 \%$ to $83.2 \%$, respectively). Female cohort participants were significantly more likely than male participants to have unsuppressed viral loads (ie, $>200$ copies $/ \mathrm{mL}$ ) at presentation to care, but this same difference was not seen when analysing most recent viral load results. Opportunistic infections (OIs) were diagnosed at or within 6 months of presentation to HIV care among $29.1 \%$ of participants who were alive at enrolment, and $6.6 \%$ presented to care with $\geq 2$ OIs. Prevalence of active HCV co-infection at enrolment is $17.5 \%$ among all participants, and slightly higher among female than male participants (19.9\% vs $16.6 \%)$. Two-fifths of participants had at least one comorbidity recorded in their clinical records, and $12.8 \%(\mathrm{n}=93)$ were living with at least two.

\section{HIV exposures among cohort participants}

Table 3 presents all self-reported HIV exposure categories recorded in participants' clinical files, analysed by sex. Although data in table 3 are organised according to an HIV 'risk hierarchy'-through which participants' primary risk exposure categories are assigned according to an established hierarchy of risk factors ${ }^{14}$-we report multiple exposure categories per individual in order to capture some of the complexity that can be missed with conventional hierarchy frameworks. ${ }^{15}$ Notably, $41.0 \%$ of female participants reported at least two possible HIV exposure categories, while $29.6 \%$ of men reported the same. Similar to trends from annual surveillance reports in Manitoba, ${ }^{2} 121316$ condomless vaginal sex is the most commonly identified exposure category. Nearly, half of the male participants $(47.6 \%)$ reported condomless 
Table 1 Sociodemographic characteristics and key outcomes of LHIV-Manitoba cohort participants, as compared with Manitoba HIV Program's client population

\begin{tabular}{|c|c|c|c|c|c|}
\hline & \multicolumn{2}{|c|}{$\begin{array}{l}\text { LHIV-Manitoba cohort } \\
(\mathrm{N}=890)\end{array}$} & \multicolumn{2}{|c|}{$\begin{array}{l}\text { Manitoba HIV Program } \\
(\mathrm{N}=1357)\end{array}$} & \multirow[b]{2}{*}{$P$ value } \\
\hline & $\mathbf{n}$ & $\%$ & $\mathbf{n}$ & $\%$ & \\
\hline \multicolumn{6}{|l|}{ Age (years) on 31 March 2019 or at time of death } \\
\hline$<18$ & 0 & 0 & 2 & 0.2 & 0.245 \\
\hline $18-24$ & 10 & 1.1 & 46 & 3.4 & 0.001 \\
\hline 25-39 & 178 & 20.0 & 358 & 26.4 & 0.001 \\
\hline 40-64 & 621 & 69.8 & 871 & 64.2 & 0.006 \\
\hline$\geq 65$ & 81 & 9.1 & 78 & 5.8 & 0.003 \\
\hline Mean (SD) & \multicolumn{2}{|c|}{$49.7(11.9)$} & \multicolumn{2}{|c|}{$46.8(12.1)$} & 0.000 \\
\hline Median (IQR) & \multicolumn{2}{|c|}{$49.8(41.5-57.5)$} & \multicolumn{2}{|c|}{$46.9(37.9-55.2)$} & 0.000 \\
\hline \multicolumn{6}{|l|}{ Sex } \\
\hline Male & 634 & 71.2 & 878 & 64.7 & 0.001 \\
\hline Female & 256 & 28.8 & 478 & 35.2 & 0.002 \\
\hline \multicolumn{6}{|l|}{ Self-identified ethnicity ${ }^{*}$} \\
\hline White & 376 & 42.4 & 407 & 36.2 & 0.000 \\
\hline Indigenous (First Nations, Inuit and Métis) & 369 & 41.6 & 448 & 39.9 & 0.000 \\
\hline Sub-Saharan African/Caribbean/black & 97 & 10.9 & 214 & 19.1 & 0.001 \\
\hline Other† & 44 & 5.0 & 54 & 4.8 & 0.307 \\
\hline \multicolumn{6}{|l|}{ Region of residence } \\
\hline Winnipeg & 719 & 80.8 & 1080 & 79.6 & 0.486 \\
\hline Central and Eastern Manitoba & 48 & 5.4 & 71 & 5.2 & 0.836 \\
\hline Southern Manitoba & 37 & 4.2 & 67 & 4.9 & 0.440 \\
\hline Western Manitoba & 35 & 3.9 & 64 & 4.7 & 0.365 \\
\hline Northern Manitoba & 30 & 3.4 & 46 & 3.4 & 1.000 \\
\hline Out of province & 12 & 1.4 & 21 & 1.6 & 0.705 \\
\hline Unknown/No known address & 9 & 1.0 & 8 & 0.6 & 0.285 \\
\hline \multicolumn{6}{|l|}{ Drug coverage at 31 March $2019 \ddagger$} \\
\hline Out-of-pocket expenses associated with drug plan & 293 & 45.4 & - & - & - \\
\hline No out-of-pocket expenses associated with drug plan & 346 & 53.6 & - & - & \\
\hline Not on treatment/unknown & 6 & 0.9 & - & - & \\
\hline \multicolumn{6}{|l|}{ Problematic substance use recorded in clinic file $\S$} \\
\hline Alcohol & 292 & 40.3 & - & - & - \\
\hline Illegal or 'street' drugsף & 222 & 31.6 & - & - & \\
\hline Alcohol and drugs & 148 & 21.1 & - & - & \\
\hline Has a primary care practitioner§ & 627 & 70.5 & - & - & - \\
\hline
\end{tabular}

*Sample sizes may not add up to total participants due to missing data for some variables.

†Includes Latin American, East/Southeast Asian, South Asian and West Asian/North African/Middle Eastern.

$\ddagger$ Variable only collected for participants alive in the fourth quarter of $2018(n=645)$.

$\S$ Variable only collected for participants alive at cohort enrolment $(n=725)$.

IIncludes cocaine, crack cocaine, heroin, crystal methamphetamine, other hallucinogens (lysergic acid diethylamide (LSD),

$\gamma$-hydroxybutyric acid (GHB), ketamine, 3,4-methylenedioxymethamphetamine (ecstasy)) and solvents such as Talwin and Ritalin and alkyl nitrates (poppers).

anal sex with other men as a possible exposure, and $4.4 \%$ reported both condomless anal sex with men and injection drug use. The majority of female participants $(92.6 \%)$ reported condomless vaginal sex as a possible exposure, and $26.2 \%$ reported injection drug use.

\section{STRENGTHS AND LIMITATIONS}

Key limitations and challenges experienced throughout the development of the LHIV-Manitoba cohort, and the particular challenges associated with developing clinical cohorts using research dollars, have been described 
Table 2 HIV-specific and other clinical indicators among LHIV-Manitoba cohort participants, by sex

\begin{tabular}{l}
$\begin{array}{l}\text { Male* } \\
(\mathrm{N}=634)\end{array}$ \\
\hline $\mathrm{n}$
\end{tabular}

Female* $^{*}$

Total*

$(\mathrm{N}=256)$

$(\mathrm{N}=890)$

$\begin{array}{lllll}\mathrm{n} & \% & \mathrm{n} & \text { P value }\end{array}$

\section{Initial CD4 count in Manitoba (cells $/ \mathrm{mm}^{3}$ )}

\begin{tabular}{|c|c|c|c|c|c|c|c|}
\hline$<200$ & 211 & 33.8 & 72 & 28.7 & 283 & 32.3 & 0.467 \\
\hline 200-350 & 151 & 24.2 & 65 & 25.9 & 216 & 24.7 & \\
\hline $351-500$ & 117 & 18.8 & 47 & 18.7 & 164 & 18.7 & \\
\hline$>500$ & 145 & 23.2 & 67 & 26.7 & 212 & 24.2 & \\
\hline Mean (SD) & \multicolumn{2}{|c|}{$328.2(248.7)$} & \multicolumn{2}{|c|}{370.5 (257.1) } & \multicolumn{2}{|c|}{$340.3(251.7)$} & \\
\hline Median (IQR) & \multicolumn{2}{|c|}{$298.5(116-478.5)$} & \multicolumn{2}{|c|}{$336(179-517)$} & \multicolumn{2}{|c|}{$316(129-492)$} & \\
\hline \multicolumn{8}{|c|}{ Last CD4 count, up to the end of 2018 (cells $/ \mathrm{mm}^{3}$ ) } \\
\hline$<200$ & 81 & 12.8 & 47 & 18.6 & 128 & 14.5 & 0.064 \\
\hline $200-350$ & 88 & 14.0 & 38 & 15.0 & 126 & 14.3 & \\
\hline $351-500$ & 130 & 20.6 & 38 & 15.0 & 168 & 19.0 & \\
\hline$>500$ & 332 & 52.6 & 130 & 51.4 & 462 & 52.3 & \\
\hline Mean (SD) & \multicolumn{2}{|c|}{$589.3(303.6)$} & \multicolumn{2}{|c|}{$331.7(302.0)$} & \multicolumn{2}{|c|}{$542.2(319.1)$} & \\
\hline Median (IQR) & \multicolumn{2}{|c|}{$565(384-768)$} & \multicolumn{2}{|c|}{256 (99-472) } & \multicolumn{2}{|c|}{517.5 (309.5-735.5) } & \\
\hline \multicolumn{8}{|c|}{ Initial viral load (copies/mL) } \\
\hline$<200$ & 329 & 54.7 & 100 & 40.3 & 429 & 50.5 & $0.001 \dagger$ \\
\hline 200-999 & 27 & 4.5 & 16 & 6.5 & 43 & 5.1 & \\
\hline 1000-99999 & 147 & 24.5 & 90 & 36.3 & 237 & 27.9 & \\
\hline $100000-999999$ & 80 & 13.3 & 36 & 14.5 & 116 & 13.7 & \\
\hline$\geq 1000000$ & 18 & 3.0 & 6 & 2.4 & 24 & 2.8 & \\
\hline Mean (SD) & \multicolumn{2}{|c|}{125778.7 (523975.9) } & \multicolumn{2}{|c|}{$107972(340114.2)$} & \multicolumn{2}{|c|}{$120577.2(477511.4)$} & \\
\hline Median (IQR) & \multicolumn{2}{|c|}{$60.9(0-38400)$} & \multicolumn{2}{|c|}{$1875(0-40$ 300) } & \multicolumn{2}{|c|}{$170(0-38800)$} & \\
\hline
\end{tabular}

Last viral load, up to the end of 2018 (copies $/ \mathrm{mL}$ )

\begin{tabular}{|c|c|c|c|c|c|c|c|}
\hline$<200$ & 491 & 84.4 & 190 & 80.2 & 681 & 83.2 & $0.517 \dagger$ \\
\hline 200-999 & 22 & 3.8 & 9 & 3.8 & 31 & 3.8 & \\
\hline 1000-99999 & 46 & 7.9 & 28 & 11.8 & 74 & 9.0 & \\
\hline 100000-999999 & 18 & 3.1 & 8 & 3.4 & 26 & 3.2 & \\
\hline$\geq 1000000$ & 5 & 0.9 & 2 & 0.8 & 7 & 0.9 & \\
\hline Mean (SD) & $40972(415359.2)$ & & \multicolumn{2}{|c|}{$27705(171693.3)$} & \multicolumn{2}{|c|}{37133.2 (362 048.3) } & \\
\hline Median (IQR) & $0(0-27.9)$ & & \multicolumn{2}{|c|}{$0(0-54.6)$} & \multicolumn{2}{|c|}{$0(0-32.4)$} & \\
\hline \multicolumn{8}{|c|}{ Opportunistic infections (OI) $\ddagger \S$} \\
\hline None & 364 & 69.9 & 150 & 73.5 & 514 & 70.9 & $0.131 \dagger$ \\
\hline $\begin{array}{l}\text { Oropharyngeal and/or } \\
\text { oesophageal candidiasis } \\
\text { (thrush) }\end{array}$ & 108 & 20.7 & 39 & 19.1 & 147 & 20.3 & \\
\hline $\begin{array}{l}\text { Pneumocystis jirovecii } \\
\text { pneumonia }\end{array}$ & 56 & 10.8 & 9 & 4.4 & 65 & 9.0 & \\
\hline Active tuberculosis & 29 & 5.6 & 14 & 6.9 & 43 & 5.9 & \\
\hline $\begin{array}{l}\text { Mycobacterium avium } \\
\text { intracellulare }\end{array}$ & 7 & 1.3 & 1 & 0.5 & 8 & 1.1 & \\
\hline Cryptococcal meningitis & 4 & 0.8 & 1 & 0.5 & 5 & 0.7 & \\
\hline
\end{tabular}

Continued 
Table 2 Continued

\begin{tabular}{|c|c|c|c|c|c|c|c|}
\hline & \multicolumn{2}{|l|}{$\begin{array}{l}\text { Male* } \\
(\mathrm{N}=634)\end{array}$} & \multicolumn{2}{|l|}{$\begin{array}{l}\text { Female* }^{*} \\
(\mathrm{~N}=256)\end{array}$} & \multicolumn{2}{|c|}{$\begin{array}{l}\text { Total* } \\
(\mathrm{N}=890)\end{array}$} & \multirow[b]{2}{*}{$P$ value } \\
\hline & $\mathbf{n}$ & $\%$ & $\mathbf{n}$ & $\%$ & $\mathbf{n}$ & $\%$ & \\
\hline Active infection (RNA+) & 105 & 16.6 & 51 & 19.9 & 156 & 17.5 & \\
\hline Past infection (RNA-/Ab+) & 32 & 5.1 & 22 & 8.6 & 54 & 6.1 & \\
\hline \multicolumn{8}{|l|}{ Comorbidities $\ddagger \emptyset$} \\
\hline None & 305 & 58.5 & 125 & 61.3 & 430 & 59.3 & $0.006 \dagger$ \\
\hline $\begin{array}{l}\text { Asthma/Chronic obstructive } \\
\text { pulmonary disease (COPD) }\end{array}$ & 93 & 17.9 & 36 & 17.7 & 129 & 17.8 & \\
\hline Hypertension & 88 & 16.9 & 24 & 11.8 & 112 & 15.5 & \\
\hline
\end{tabular}

*Sample sizes may not add up to total participants due to missing data for some variables.

†Some expected values $<5$, so $p$ values must be interpreted with caution.

$\ddagger$ Variable only collected for participants who were alive at cohort enrolment: male, $n=521$; female, $n=204$ and total, $n=725$.

$\S$ Diagnosed at, or within 6 months of presentation to care with the Manitoba HIV Program. Sum of categories exceeds total sample size because some participants presented with $\geq 1$ OI.

IS

in detail elsewhere. ${ }^{17}$ Briefly, a number of participants expressed apprehension about the kinds of data that would be collected as a result of their involvement with the cohort, and in response, study staff made a point to spend adequate time to clearly explain the processes through which the study is able to link clinical and administrative data while maintaining confidentiality. Additionally, efficiently implementing study protocols without disrupting existing clinic operations was another substantial challenge; incorporating additional procedures related to cohort enrolment into routine encounters was difficult for healthcare providers who are working within busy HIV clinics. The study team regularly engages with providers to highlight the benefits that the cohort may confer to their own practice, their clients' needs and the operations of Manitoba HIV Program.

Because enrolment protocols are clinic based, this cohort may not be representative of people living with HIV who are suboptimally engaged in care. As enrolment efforts move forward, it will be important for the study team to consider strategies to increase the proportion of participants belonging to demographic subgroups who are currently underrepresented in the cohort. It is of particular interest to the study team to understand whether certain subgroups are less likely to consent to cohort participation, and if so, why. While findings from the cohort will still be important for informing care programming and policy decisions for the province, generalisability may be limited, and results must be interpreted accordingly. One key strategy to circumvent the misinterpretation of analyses derived from cohort data will be to involve Manitoba HIV Program's clients and their providers in the analysis, interpretation and knowledge translation processes.

The LHIV-Manitoba cohort is the first comprehensive source of health data compiled from people living with HIV in the province and will provide important opportunities for systematically and comprehensively understanding clinical care needs, gaps and outcomes of Manitobans living with HIV. Importantly, Manitoba is well positioned to undertake large, population-based linkage studies given the existence of a single insurer (MHSAL) that is responsible for payment of most health services, and the existence of linkable, population-based administrative health databases through the Manitoba Centre for Health Policy. ${ }^{18}{ }^{19}$ The cohort also identifies common comorbidities such as diabetes and hypertension, where further assessment of outcomes offers opportunities for targeted resource allocation for improved management. Furthermore, the Manitoba HIV Program embodies a unique care model-comprising both specialist and primary care services-that closely aligns with the PatientCentred Medical Home model of HIV care. ${ }^{20}$ As such, findings from the LHIV-Manitoba cohort will be able to speak to the growing body of literature focusing on holistic models of HIV care delivery. ${ }^{20} 21$

Finally, because the clinical cohort is embedded within the Manitoba HIV Program, and stakeholders within MHSAL and the community of people with lived experience have been actively involved in its development, we also expect that data from the cohort will facilitate epidemiological analyses that can inform both HIV care programming and provincial policy on adequately resourcing HIV-related health services. 
Table 3 Self-identified HIV exposure categories among LHIV-Manitoba cohort participants, by sex

\begin{tabular}{|c|c|c|c|c|c|c|c|}
\hline & \multicolumn{2}{|c|}{$\begin{array}{l}\text { Male* }^{*} \\
(\mathrm{~N}=634)\end{array}$} & \multicolumn{2}{|c|}{$\begin{array}{l}\text { Female* }^{*} \\
(\mathrm{~N}=256)\end{array}$} & \multicolumn{2}{|c|}{$\begin{array}{l}\text { Total } \\
(\mathrm{N}=890)\end{array}$} & \multirow[b]{2}{*}{$P$ value } \\
\hline & $\mathbf{n}$ & $\%$ & $\mathbf{n}$ & $\%$ & $\mathbf{n}$ & $\%$ & \\
\hline Condomless anal sex between males+injection drug use & 28 & 4.4 & - & - & 28 & 3.1 & - \\
\hline Condomless anal sex between males & 302 & 47.6 & - & - & 302 & 33.9 & - \\
\hline Recipient of blood/blood product & 3 & 1.0 & - & - & 3 & 0.3 & \\
\hline Condomless vaginal sex & 50 & 16.6 & - & - & 50 & 5.6 & \\
\hline Possible exposure in an HIV-endemic country $†$ & 5 & 1.7 & - & - & 5 & 0.6 & \\
\hline Occupational exposure & 2 & 0.7 & - & - & 2 & 0.2 & \\
\hline Injection drug use & 126 & 19.9 & 67 & 26.2 & 193 & 21.7 & 0.039 \\
\hline Recipient of blood/blood product & 5 & 4.0 & 2 & 3.0 & 7 & 0.8 & \\
\hline Condomless vaginal sex & 80 & 63.5 & 56 & 83.6 & 136 & 15.3 & \\
\hline Possible exposure in an HIV-endemic country $†$ & 1 & 0.8 & 0 & 0 & 1 & 0.1 & \\
\hline Occupational exposure & 1 & 0.8 & 1 & 1.5 & 2 & 0.2 & \\
\hline Recipient of blood/blood product & 18 & 2.0 & 8 & 0.9 & 26 & 2.9 & 0.248 \\
\hline Condomless vaginal sex & 11 & 61.1 & 6 & 75.0 & 17 & 1.9 & \\
\hline Possible exposure in an HIV-endemic country $†$ & 2 & 11.1 & 1 & 12.5 & 3 & 0.3 & \\
\hline Occupational exposure & 1 & 5.6 & 2 & 25.0 & 3 & 0.3 & \\
\hline Condomless vaginal sex & 331 & 52.2 & 237 & 92.5 & 568 & 63.8 & $<0.001$ \\
\hline Possible exposure in an HIV-endemic country $†$ & 35 & 10.6 & 40 & 15.6 & 75 & 8.4 & \\
\hline Occupational exposure & 2 & 0.6 & 4 & 1.7 & 6 & 0.7 & \\
\hline Occupational exposure & 5 & 0.8 & 4 & 1.6 & 9 & 1.0 & 0.285 \\
\hline Possible exposure in an HIV-endemic country & 0 & 0 & 0 & 0 & 0 & 0 & \\
\hline Possible perinatal acquisition & 1 & 0.2 & 0 & 0 & 1 & 0.1 & - \\
\hline Possible exposure in an HIV-endemic country $†$ & 1 & 100 & - & - & 1 & 0.1 & \\
\hline Other/unknown & 16 & 2.5 & 7 & 2.7 & 23 & 2.6 & 0.864 \\
\hline \multicolumn{8}{|l|}{ Number of potential HIV exposures recorded } \\
\hline 1 & 446 & 70.4 & 151 & 59.0 & 597 & 67.1 & $<0.001$ \\
\hline 2 & 172 & 27.1 & 102 & 39.8 & 274 & 30.8 & \\
\hline$\geq 3$ & 16 & 2.5 & 3 & 1.2 & 19 & 2.1 & \\
\hline
\end{tabular}

*Sum of categories exceeds total sample size because participants may have $\geq 1 \mathrm{HIV}$ exposure category reported in clinical file. †Possible exposure in an HIV-endemic country is never assigned as a primary exposure category, but is captured as an additional exposure category if an individual was born in, or spent considerable time living/working in an HIV-endemic country and experienced a potentially 'risky' event.

\section{FUTURE PLANS}

Future analyses using clinical cohort data will focus on areas that have been identified as specific points of interest for the Manitoba HIV Program, namely, generating a better understanding of the impact of existing provincial drug plans on clinical outcomes and exploring, for the first time in the province, characteristics and determinants of mortality among people living with HIV. Additionally, the cohort data are currently being used to generate Manitoba-specific HIV care cascade estimates, ${ }^{22-24}$ which will be presented in detail in a forthcoming manuscript. The subsequent work will examine the local HIV care cascade through an equity lens to better understand how different groups of participants experience HIV care and treatment outcomes differently within Manitoba.
Author affiliations

${ }^{1}$ Institute for Global Public Health, University of Manitoba, Winnipeg, Manitoba, Canada

${ }^{2}$ Nine Circles Community Health Centre, Winnipeg, Manitoba, Canada

${ }^{3}$ C.T. Lamont Primary Health Care Research Centre, Bruyère Research Institute, Ottawa, Ontario, Canada

${ }^{4}$ Community Scholar, Winnipeg, Manitoba, Canada

${ }^{5}$ Manitoba Health, Seniors and Active Living, Government of Manitoba, Winnipeg,

Manitoba, Canada

${ }^{6}$ Department of Internal Medicine, University of Manitoba, Winnipeg, Manitoba, Canada

${ }^{7}$ Department of Medical Microbiology and Infectious Diseases, University of Manitoba, Winnipeg, Manitoba, Canada

Acknowledgements The authors thank Dr Christopher Briggs, Dr Elsabé du Plessis, Nicole Herpai, Stella Leung, Michael Paillé and Dr Souradet Shaw for their help with participant enrolment, data collection and/or data analyses. This work 
would not be possible without the staff and providers within the Manitoba HIV Program - their support and tireless efforts throughout cohort development and participant recruitment continue to be invaluable. We also acknowledge and thank our partners at MHSAL's Information Management \& Analytics unit and Cadham Provincial Laboratory for their collaboration and support with administrative data extraction. Finally, the support and guidance we have received from the LHIV Study team, especially the LHIV Community Scholars, and the Nine Circles Community Health Centre Research Committee have been invaluable to the continuation of this work.

Contributors LMM, EC, CK and MB: study conceptualisation and design. LMM, LI, $\mathrm{KK}, \mathrm{YK}$ and MB: data collection and acquisition. LMM: data analysis and drafting of the manuscript. LMM, CK, YK, JB and MB: data interpretation. EC, LI, CK, CB, CL, YK, $\mathrm{KK}, \mathrm{JB}$ and MLB: critical revisions and final approval.

Funding The LHIV Study is funded by CIHR (funding reference no. TT5-128270). LMM received funding from the CIHR Canada Graduate Scholarship Doctoral Award, CIHR Michael Smith Foreign Study Supplement, the University of Manitoba, and the Canadian Association for HIV Research to support this work.

Competing interests None declared.

Patient and public involvement Patients and/or the public were involved in the design, or conduct, or reporting, or dissemination plans of this research. Refer to the Methods section for further details.

Patient consent for publication Not required.

Ethics approval The LHIV-Manitoba cohort study received ethics approval from the University of Manitoba's Health Research Ethics Board, the local hospital's Research Impact Committee and the Health Information Privacy Committee of Manitoba Health, Seniors and Active Living. This work has also received support from the Health Information Research Governance Committee of Nanaandawewigamig, the First Nations Health and Social Secretariat of Manitoba.

Provenance and peer review Not commissioned; externally peer reviewed.

Data availability statement Data are available upon reasonable request. Researchers interested in accessing data related to the LHIV-Manitoba cohort should be directed to Dr Marissa Becker (marissa.becker@umanitoba.ca). All access requests for individual-level data must be accompanied by proposals for the research projects and will be subject to approvals by Health Research Ethics Board at the University of Manitoba, as well as the researchers' home institution. Aggregate and/or deidentified data may be shared with fewer restrictions pending review by the LHIV study team.

Open access This is an open access article distributed in accordance with the Creative Commons Attribution Non Commercial (CC BY-NC 4.0) license, which permits others to distribute, remix, adapt, build upon this work non-commercially, and license their derivative works on different terms, provided the original work is properly cited, appropriate credit is given, any changes made indicated, and the use is non-commercial. See: http://creativecommons.org/licenses/by-nc/4.0/.

ORCID iD

Leigh M McClarty http://orcid.org/0000-0003-0183-2768

\section{REFERENCES}

1 Haddad N, Li JS, Totten S, et al. HIV in Canada-Surveillance report, 2017. Can Commun Dis Rep 2018;44:324-32.

2 Government of Manitoba. 2017 annual statistical update: HIV in Manitoba. Winnipeg: Manitoba Health, Seniors and Active Living, Epidemiology and Surveillance, 2018.
3 Government of Saskatchewan. HIV prevention and control report 2017. Ministry of Health, Population Health Branch, 2018.

4 Bourgeois AC, Edmunds M, Awan A, et al. Hiv in CanadaSurveillance report, 2016. Can Commun Dis Rep 2017;43:248-56.

5 Public Health Agency of Canada. HIV and AIDS in Canada: surveillance report to December 31, 2014. Ottawa: Minister of Public Works and Government Services Canada, 2015

6 Becker ML, Kasper K, Pindera C, et al. Characterizing the HIV epidemic in the prairie provinces. Can J Infect Dis Med Microbiol 2012;23:19-22.

7 Heath K, Samji H, Nosyk B, et al. Cohort profile: seek and treat for the optimal prevention of HIV/AIDS in British Columbia (stop HIV/ AIDS BC). Int J Epidemiol 2014;43:1073-81.

8 Rourke SB, Gardner S, Burchell AN, et al. Cohort profile: the Ontario HIV treatment network cohort study (OCS). Int J Epidemiol 2013;42:402-11.

9 Kendall CE, Shoemaker ES, Crowe L, et al. Engagement of people with lived experience in primary care research: living with HIV innovation team community Scholar program. Can Fam Physician 2017;63:730-1.

10 Manitoba Centre for Health Policy. Concept: administrative health data. Winnipeg, Canada: University of Manitoba, 2010. http:// mchp-appserv.cpe.umanitoba.ca/viewConcept.php?conceptID= 1420

11 Finlayson GS, Lix LM, Roos LL. The whole is greater than the sum of the parts: using data linkage and cohort designs to create data synergy at MCHP. Healthc Policy 2011;6:83-5.

12 Manitoba HIV Program. 2016 Manitoba HIV program update. Winnipeg, 2017.

13 Manitoba HIV Program. 2017 Manitoba HIV program update. Winnipeg: Nine Circles Community Health Centre, 2018.

14 Public Health Agency of Canada. HIV and AIDS in Canada: surveillance report to December 31, 2013. Ottawa: Public Health Agency of Canada, 2014.

15 Schmidt MA, Mokotoff ED. HIV/AIDS surveillance and prevention: improving the characterization of HIV transmission. Public Health Rep 2003;118:197-204.

16 Government of Manitoba. 2016 annual statistical update: HIV and AIDS. Winnipeg: Manitoba Health, Seniors and Active Living, 2018.

17 Shoemaker ES, Becker ML, Liddy CE, et al. Creating clinical cohorts: challenges encountered in two Canadian provinces. Healthc Policy 2019;15:11-8.

18 Manitoba Centre for Health Policy. Manitoba Population Research Data Repository - Overview Winnipeg. Canada: University of Manitoba, 2019. http://umanitoba.ca/faculties/health_sciences/ medicine/units/chs/departmental_units/mchp/resources/repository/ index.html

19 Roos LL, Nicol JP. A research registry: uses, development, and accuracy. J Clin Epidemiol 1999:52:39-47.

20 Kendall CE, Shoemaker ES, Porter JE, et al. Canadian HIV care settings as patient-centered medical homes (PCMHs). J Am Board Fam Med 2019;32:158-67.

21 Byrd KK, Hou JG, Bush T, et al. Adherence and viral suppression among participants of the patient-centered human immunodeficiency virus (HIV) care model project: a collaboration between communitybased pharmacists and HIV clinical providers. Clin Infect Dis 2020;70:789-97.

22 Wilton J, Broeckaert L. The HIV treatment cascade - patching the leaks to improve HIV prevention. Prevention in Focus. Toronto: CATIE, 2013.

23 Nosyk B, Montaner JSG, Colley G, et al. The cascade of HIV care in British Columbia, Canada, 1996-2011: a population-based retrospective cohort study. Lancet Infect Dis 2014;14:40-9.

24 Gardner EM, Young B. The HIV care cascade through time. Lancet Infect Dis 2014;14:5-6. 